\title{
Protective Effect of Enterococcus faecium SF68 and Saccharomyces boulardii in Acute Severe Diarrhea in Infants: Randomized Controlled Trial
}

\author{
Fariha Ahmad Khan, ${ }^{1}$ Muhammad Zeeshan Khan, ${ }^{2}$ Abdul Mudabbir Rehan, ${ }^{3}$ Zoobia Irum, \\ Fouzia Perveen, ${ }^{5}$ Sadia Chiragh ${ }^{6}$
}

\begin{abstract}
Objectives: This study was done to observe the effect of Enterococcus faecium SF68 and Saccharomyces boulardii in acute severe diarrhea in infants.

Methods: It was a single blind, randomized controlled clinical trial done in Children Hospital, Lahore. The infants were selected between 6 months to 12 months of age. All the infants were suffering from acute diarrhea with severe dehydration. Total 105 infants were selected and randomly divided into three groups having 35 infants in each group. Infants in group A received standard treatment of diarrhea. Infants in group B and C received Enterococcus faecium SF68 and Saccharomyces boulardii respectively twice daily for five days along with standard treatment of diarrhea. All the infants were monitored for five days. The treatment response was observed in terms of frequency of diarrhea, duration of diarrhea, stool consistency and length of hospital stay.

Results: The frequency of diarrhea, duration of diarrhea and length of hospital stay were significantly reduced in both group $\mathrm{B}$ and $\mathrm{C}$ as compared to group $\mathrm{A}$.

Conclusion: Enterococcus faecium SF68 and Saccharomyces boulardii helped to reduce the stool frequency, duration of diarrhea, length of hospital stay and also improved the stool consistency in acute severe diarrhea in infants.

Key Words: Probiotics, Enterococcus faecium SF68, Saccharomyces boulardii, Acute severe Diarrhoea

How to Cite: Ahmad F.K, Zeeshan M.K, Mudabbir A.R, Irum Z, Perveen F, Chiragh S. Protective Effect of Enterococcus Faecium Sf68 and Saccharomyces Boulardii in Acute Severe Diarrhea in Infants: Randomized Controlled Trial. Esculapio.2020;16(04):59-65.
\end{abstract}

DOI: https://doi.org/10.51273/esc20.2516413

\section{Introduction}

$\mathrm{D}$ iarrhea is defined as "the passage of 3 or more loose or liquid stools per day or more frequently than is normal for the individual." In acute diarrhea, there is sudden onset of excessively loose stools $>10 \mathrm{ml} / \mathrm{kg} /$ day in children less than 1 year of age and $>200 \mathrm{~g} / 24$ hours in older children, which lasts less than 14 days. ${ }^{1}$ The data of World Health

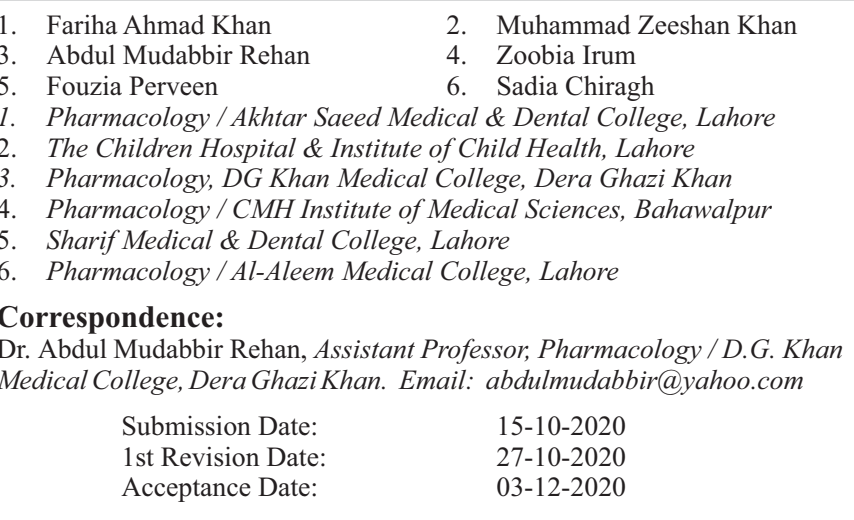

Organization (WHO) reveal that there are 2 billion cases of diarrhea throughout the world each year and 1.9 million children under the age of 5 years perish from diarrhea every year, commonly in developing countries. The fluid and electrolyte replacement is primary treatment of diarrhea. Zinc supplements are recommended along with oral rehydrating salt (ORS) in diarrhea as they decrease the duration of diarrhea. The antibiotic treatment is controversial in the treatment of diarrhea, but there are certain infections for which treatment is mandatory. ${ }^{2}$

Probiotics are live microorganisms, which maintain a balance between the immune system and gastrointestinal tract. They are available in different forms as tablets, powders and capsules. They have antimicrobial activity against pathogenic bacteria and produce compounds which kill the pathogenic bacteria. ${ }^{3}$ Enterococci are part of the microflora of intestine of animals and humans. Enterococcus 
faecium SF68 is the probiotic strain that can be used in the treatment of diarrhea. Saccharomyces boulardii is included in the yeast familyand it is the principal probiotic yeast. The $\mathrm{S}$. boulardii can be used in the management of acute diarrhea as well as antibiotic associated diarrhea. ${ }^{4}$ The future studies should be done to put emphasis on best dosage of S. boulardii in diarrhea from different causes as some studies did not specify the dose of S. boulardii in diarrhea from various causes. ${ }^{5}$ Trials with probiotic Entercoccus faecium SF68 in humans are limited and results show variations.

Few studies have been conducted in developing countries regarding the use of probiotics in diarrhea and most of the studies have not provided Zn as part of the treatment. Therefore well designed (randomized controlled trial) RCTs should be done in developing countries to compare the recommended treatment of diarrhea i.e. ORS, Zn supplements and continued feeding, with and without adding probiotics. ${ }^{6}$ Most of the studies which have been done on probiotics included only mild to moderate diarrhea when there is no dehydration or some dehydration and the studies which were done on severe diarrhea showed no beneficial effect. ${ }^{7}$ There is a need to study the efficacy of probiotics in severe diarrhea in developing countries. In this study the effect of two different probiotics i.e. Enterococcus faecium SF68 and S. boulardii have been evaluated in acute severe diarrhea in infants.

\section{Methods}

It was a prospective, single blind, randomized controlled clinical trial. The trial was conducted in Children Hospital, Lahore from July 2016 to November 2016 after being reviewed and approved by Ethical Committee. The sample was calculated by using $90 \%$ power of study and 5\% level of significance. It was calculated by taking mean $\pm \mathrm{SD}$ of number of stools/day with standard treatment versus standard treatment with probiotic in children. ${ }^{8}$ According to this formula sample size was 32 . We included 35 infants in each group. The infants with age range of 6 months to 12 months suffering from acute diarrhea with severe dehydration were included in the study. Dehydration was severe (more than 10\%) when there was rapid or weak pulse, low blood pressure, sunken eyes and lack of urine output. The exclusion criteria were; infants with any chronic disease, typhoid fever, blood in stools, infant having severe malnutrition and who have been given probiotics within last 10 days. Non-probability, purposive sampling was done for selection of patients. An independent person not affiliated with this study randomized 105 infants into three groups of 35 infant in each group through simple randomisation by using random number list generated by computer. The person who randomised the infants also prepared the envelopes in which treatment plan of the infants was present. The parents received sealed and packed envelopes according to randomisation list. The serial number of the infants with name and age was mentioned on the envelopes. The envelopes were opened, and the infants were put in their specific groups. In this way treatment plan was concealed from the researcher until intervention started. The parents of the infants were kept blind and they did not know in which group infants were put. After enrollment, baseline lab investigations i.e. complete blood count, serum electrolytes and renal functions tests were done for all infants. In group A, which was a control group, infants were given only standard treatment of diarrhea, i.e., ORS, IV fluids and $\mathrm{Zn}$ supplements. Antimicrobial treatment was only given when needed. ${ }^{2}$ Infants in group B were given standard treatment as well as probiotic Enterococcus faecium SF 68, one capsule every 12 hours for five days. Contents of capsule were mixed in $20 \mathrm{ml}$ water for administration. ${ }^{9}$ Infants in group C were given standard treatment of diarrhea as well as probiotic $\mathrm{S}$. boulardii, one capsule of $250 \mathrm{mg}$ every 12 hours for five days. Contents of capsule were mixed in $20 \mathrm{ml}$ water for administration. ${ }^{10}$ The probiotics were given to the infants as soon as the infants were able to take orally. The following parameters were observed: Frequency of diarrhea, Duration of diarrhea, Stool consistency, Length of hospital stay. Infant was defined as recovered from diarrhea when 8 hours had passed after passage of stool with normal consistency or infant had been discharged. ${ }^{8}$ Stool consistency was classified as normally formed stool, soft stool, semi liquid and liquid and was graded according to classification as 1, 2, 3, 4 respectively. ${ }^{11}$ Infant was discharged when he or she was recovered from diarrhea. If diarrhea was prolonged, infant was discharged after five days as we had monitored parameters for five days, but total duration of diarrhea was noted for which infants were inquired telephonically daily. The data collected was 
processed by using Statistical Package for Social Sciences. The data was checked for normal distribution by Shaprio Wilk test. The data was normally distributed. Quantitative variables were presented in mean and SD. ANOVA was used to analyze the significance between three groups and post hoc Tukey's test was used for pairwise comparison between the groups. Qualitative variables were presented as frequencies and proportions. Chi square test was applied for qualitative variables. $p$ value $<0.05$ was considered significant.

\section{Results}

The Table. 1 summarizes the mean \pm standard deviation of various demographic parameters of all study groups. The infants were included with age range 6 to 12 months. Mean weight of the patients was in between 15 th to 50 th percentile. The Table 2 summarizes the mean \pm standard deviation of frequency of diarrhea and other associated symptoms in all study group at the time of admission. Almost all of the patients had more than ten episodes of diarrhea per day. The $100 \%$ of patients had stool with liquid consistency. Figure 1 illustrates the post-treatment comparison of mean \pm standard deviation of change in pattern of number of stools in all study groups over a period of 5 consecutive days.

The comparison of means of all groups by ANOVA revealed a significant difference between the group

Table 1: Demographic Data of Patients in all Study Groups

\begin{tabular}{cccc}
\hline $\begin{array}{c}\text { Demographic } \\
\text { data }\end{array}$ & $\begin{array}{c}\text { Group A } \\
\text { (Control) }\end{array}$ & $\begin{array}{c}\text { Group B } \\
\text { (SF68) }\end{array}$ & $\begin{array}{c}\text { Group C } \\
\text { (S. boulardii) }\end{array}$ \\
\hline $\begin{array}{c}\text { Age (months) } \\
\text { (mean } \pm \text { SD) }\end{array}$ & $8.64 \pm 2.37$ & $8.64 \pm 2.18$ & $9.3 \pm 2.4$ \\
$\begin{array}{c}\text { Weight (kg) } \\
(\text { mean } \pm \text { SD) } \\
\text { Male }\end{array}$ & $7.4 \pm 0.93$ & $7.41 \pm 0.94$ & $7.67 \pm 0.85$ \\
n (\%) & $24(68.6 \%)$ & $21(60 \%)$ & $18(51.4 \%)$ \\
$\begin{array}{c}\text { Female } \\
\text { n (\%) }\end{array}$ & $11(31.4 \%)$ & $14(40 \%)$ & $17(48.6 \%)$ \\
$\begin{array}{c}\text { Rural Areaw } \\
\text { n (\%) }\end{array}$ & $14(40 \%)$ & $7(20 \%)$ & $6(17.1 \%)$ \\
$\begin{array}{c}\text { Urban Area } \\
\text { n (\%) }\end{array}$ & $21(60 \%)$ & $28(80 \%)$ & $29(83 \%)$ \\
\hline
\end{tabular}

means with a $p$ value of $<0.001$.

The number of stools passed by the infants in group A was much higher as compared to infants in group B and group $\mathrm{C}$. The difference was significant between group A and group B from day 1 (after $24 \mathrm{hrs)} \mathrm{to} \mathrm{day} 5$. The difference was not significant between group A and group C on day 1 (after $24 \mathrm{hrs}$ ) but difference was
Table 2: History of diarrhea and associated symptoms at the time of admission

\begin{tabular}{cccc}
\hline $\begin{array}{c}\text { History of } \\
\text { patients }\end{array}$ & $\begin{array}{c}\text { Group A } \\
\text { (Control) }\end{array}$ & $\begin{array}{c}\text { Group B } \\
\text { (SF68) }\end{array}$ & $\begin{array}{c}\text { Group C } \\
\text { (S. boulardii) }\end{array}$ \\
\hline $\begin{array}{c}\text { No. of stool before } \\
\text { treatment of } \\
\text { diarrhea } \\
\text { (mean } \pm \text { SD) } \\
\text { Fever } \\
\text { n (\%) }\end{array}$ & $12.71 \pm 3.25$ & $11.28 \pm 3.01$ & $11.25 \pm 2.91$ \\
$\begin{array}{c}\text { Vomiting } \\
\text { n }(\%)\end{array}$ & $29(82.9 \%)$ & $27(77 \%)$ & $31(88.6 \%)$ \\
\hline
\end{tabular}

significant between group A and group C from day 2 to day 5 .

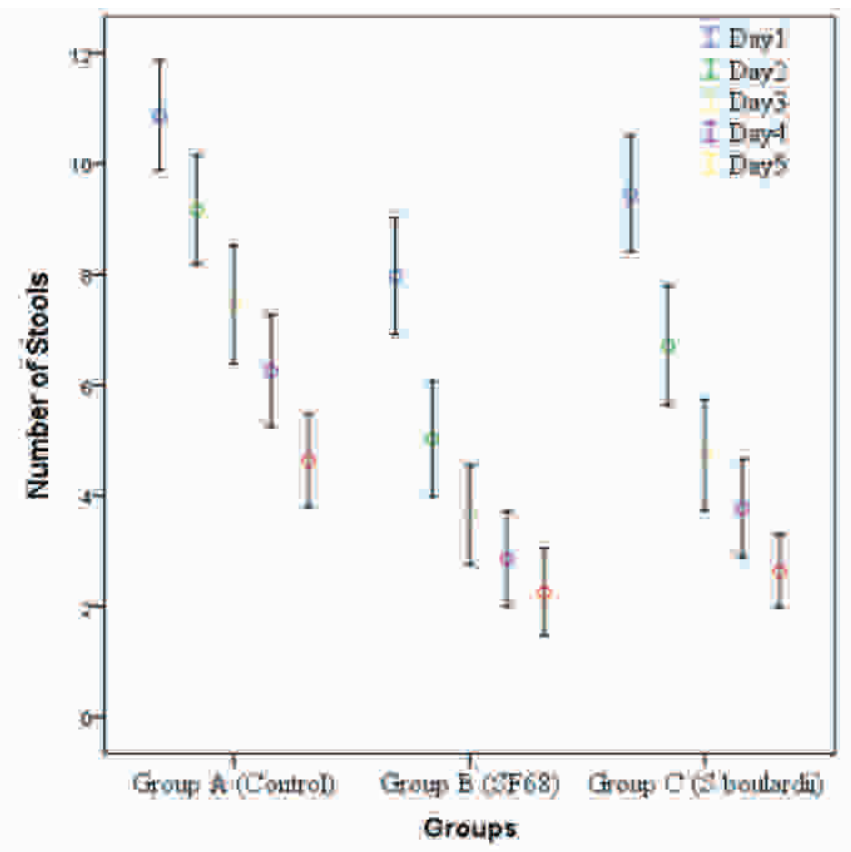

Figure. 1: No. of Stools After Treatment

Table. 3 summarizes the post-treatment comparison of mean \pm standard deviation of stool consistencies in all study groups over a period of 5 consecutive days. There was significant difference in improvement of stool consistency among groups. Patients in group B and group $\mathrm{C}$ started passing normal stools earlier as compared to patients in group A. At day 5, $80 \%$ of patients had normal stool in group B while $60 \%$ of patients had normal stool in group $\mathrm{C}$ as compared to $23 \%$ in group $\mathrm{A}$.

Table. 4 summarizes the post-treatment comparison of mean \pm standard deviation of duration of diarrhea in all study groups. The duration of diarrhea was higher in group A as compared to group B and group C. There was no significant difference between group B and group $\mathrm{C}$ in terms of duration of diarrhea.

Table 5 summarizes the post-treatment comparison 
Table 3: Number (\%) of patients with different stool consistencies

\begin{tabular}{|c|c|c|c|c|c|c|}
\hline & Stool Consistency & Day1 & Day2 & Day3 & Day4 & Day5 \\
\hline \multirow[t]{3}{*}{ Group A (control) } & Normal & & & & $3(8.6 \%)$ & $8(22.9 \%)$ \\
\hline & Soft & & & $5(14.3 \%)$ & $6(17.1 \%)$ & $9(25.7 \%)$ \\
\hline & Liquid & $34(97.1)$ & $28(80 \%)$ & $25(71.4 \%)$ & $11(31.4 \%)$ & $2(5.7 \%)$ \\
\hline \multirow{3}{*}{$\begin{array}{c}\text { Group B } \\
\text { (SF68) }\end{array}$} & Normal & & & & $19(54.3 \%)$ & $28(80 \%)$ \\
\hline & Soft & & $15(42.9)$ & $23(65.7 \%)$ & $11(31.4 \%)$ & $3(8.6 \%)$ \\
\hline & Liquid & $21(60 \%)$ & $10(28.6 \%)$ & $4(11.4 \%)$ & $3(8.6 \%)$ & $1(2.9 \%)$ \\
\hline \multirow{4}{*}{$\begin{array}{c}\text { Group C } \\
\text { (S. boulardii) }\end{array}$} & Normal & & & $1(2.9 \%)$ & $10(28.6 \%)$ & $21(60 \%)$ \\
\hline & Soft & & $7(20 \%)$ & $17(48.6 \%)$ & $13(37.1 \%)$ & $8(22.9 \%)$ \\
\hline & Semi Liquid & $7(20 \%)$ & $9(25.7 \%)$ & $10(28.6 \%)$ & $8(22.9 \%)$ & $5(14.3 \%)$ \\
\hline & Liquid & $28(80 \%)$ & $19(54.3 \%)$ & $7(20 \%)$ & $4(11.4 \%)$ & $1(2.9 \%)$ \\
\hline
\end{tabular}

Table 4: Duration of diarrhea (hours)

\begin{tabular}{ccccc}
\hline Groups & N & Mean & $\begin{array}{c}\text { Standard } \\
\text { Deviation }\end{array}$ & $\boldsymbol{p}$ value \\
\hline $\begin{array}{c}\text { Group A } \\
\text { (Control) }\end{array}$ & 35 & 130.37 & 63.11 & \\
$\begin{array}{c}\text { Group B } \\
\text { (SF68) }\end{array}$ & 35 & 54.26 & 56.36 & $<0.001$ \\
$\begin{array}{c}\text { Group C } \\
\text { (S. boulardii) }\end{array}$ & 35 & 71.71 & 53.32 & \\
\hline
\end{tabular}

of mean \pm standard deviation of length of hospital stay in all study groups. The length of hospital stay was higher in group A as compared to group B and group C. There was no significant difference between group $\mathrm{B}$ and group $\mathrm{C}$ in terms of length of hospital stay.

Figure 2 illustrates the post-treatment comparison of mean \pm standard deviation of episodes of vomiting in all study groups over a period of 5 consecutive days. The comparison of means of all groups by ANOVA revealed a significant difference between the group means with a $p$ value of $<0.001$. The patients in group $\mathrm{B}$ had less episodes of vomiting as compared to patients in group $\mathrm{C}$ at day 1 and at day 2 only.

Figure 3 illustrates the post-treatment comparison of mean \pm standard deviation of body temperature in all study groups over a period of 5 consecutive days. The comparison of means of all groups by ANOVA revealed a significant difference between the group means with a $p$ value of $<0.001$. Body temperature difference was significant only at day 2 after treatment when the patients in group A had high fever as compared patients in group B and group $\mathrm{C}$ while the difference was not significant between group $\mathrm{B}$ and group C.

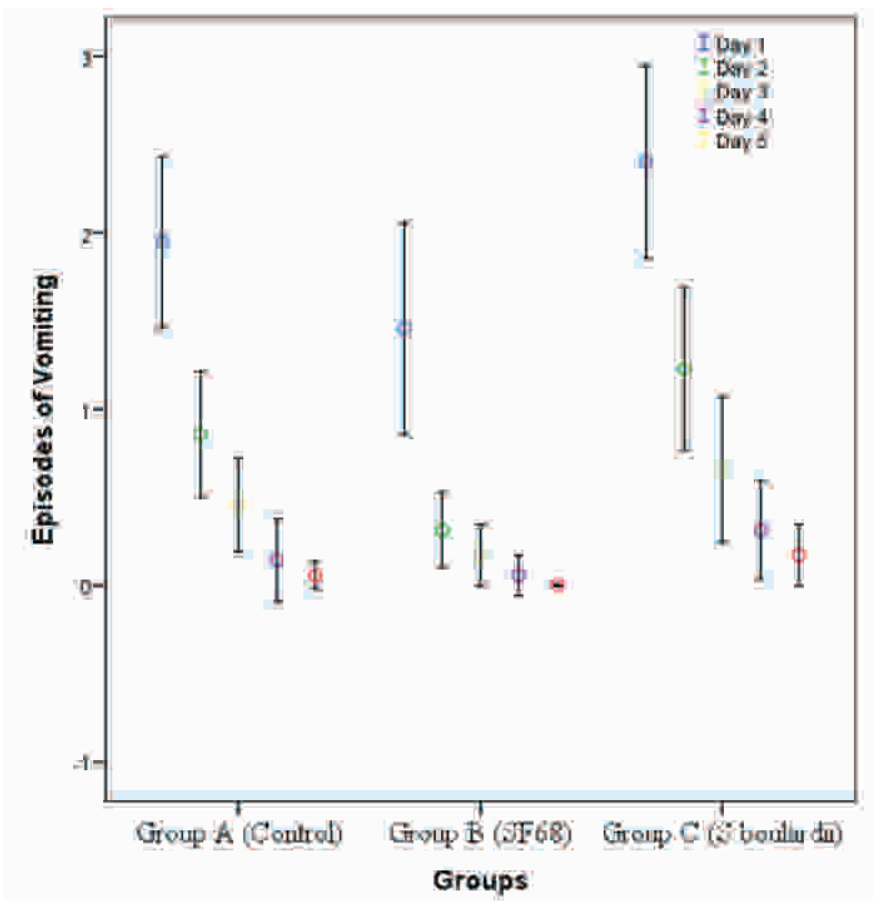

Figure 2: Episodes of Vomiting After Treatment

Table 5: Length of hospital stay (days)

\begin{tabular}{ccccc}
\hline Group & N & Mean & $\begin{array}{c}\text { Standard } \\
\text { Deviation }\end{array}$ & $\boldsymbol{p}$ value \\
\hline Group A (Control) & 35 & 4.16 & 1.14 & \\
Group B (SF 68) & 35 & 2.18 & 1.38 & $<0.001$ \\
Group C (S. boulardii) & 35 & 2.9 & 1.42 & \\
\hline
\end{tabular}

\section{Discussion}

This study was a single blind randomized controlled clinical trial carried out in Children Hospital, Lahore. Protective effects of two different probiotics in acute severe diarrhea in infants were compared with standard treatment of diarrhea as well as with each other. Total 105 patients were selected, and each group had 35 patients. The age of patients was between 6 to 12 
months. This age group was selected as hospitalization associated with diarrhea is common in this age group. ${ }^{12,13}$ The patients were having severe dehydration at the time of admission and needed IV fluids. All the patients were followed for a period of five days. All the patients received complete intervention. No patient was dropped from the study after selection. The patients in group A received only standard treatment of diarrhea and it was a control group. The patients in group B received standard treatment of diarrhea as well as probiotic Enterococcus faecium SF68 and patients in group C received standard treatment of diarrhea as well as probiotic S. boulardii.

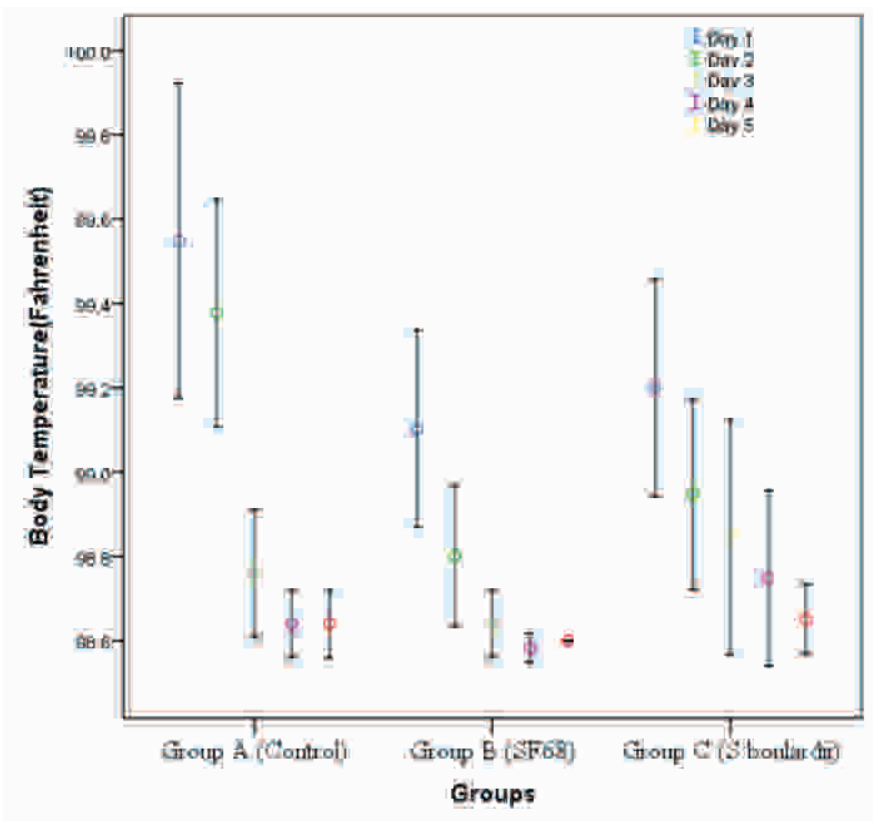

Figure 3: Body Temperature in Study Groups After Treatment

Randomized controlled trials have been done on the effect of S. boulardii in diarrhea and most of these trials showed positive results in decreasing the duration of diarrhea. ${ }^{14-17}$ Another study was done in Turkey to compare the effect of two probiotics i.e., S. boulardii and Bifidobacterium lactis in acute diarrhea in addition to standard treatment of diarrhea in children. However, in this study, there was no significant difference in duration of diarrhea and vomiting in control group and the group in which $\mathrm{S}$. boulardii was given. ${ }^{18}$ In present study, S. boulardii was given to patients of group $\mathrm{C}$. There was significant difference in stool frequency between group A and group C as stool frequency was reduced in a group receiving $\mathrm{S}$. boulardii. The mechanism by which S. boulardii decrease the duration of diarrhea depends upon the stimulatory effects on the mucosa of intestine, protective action against inflammation and inhibitory action of bacterial toxins. ${ }^{19,20}$ Studies on effect of probiotic Entero-cccus Faecium SF68 in diarrhea in children are limited. One study was done in Switzerland to evaluate the efficacy of Enterococcus faecium SF68 in diarrhea and it showed a decrease in duration of diarrhea in children. ${ }^{21}$ Another study was done in Italy to assess the efficacy of five probiotic preparations iin children suffering from. ${ }^{9}$ Patients were randomly assigned to receive one of five interventions. The control group received only ORS. The other four groups were randomly assigned to receive one of four probiotic preparations in addition to standard treatment of diarrhea. However there was no significant difference in parameters between control group and the groups receiving S. boulardii and Enterococcus faecium SF68. This is contradictory to results of present study. Mechanism of action of Enterococcus faecium SF68 may depend upon the immune system of the body as one study done on animals showed that this probiotic stimulated the immune functions of the host as the group of animals which received the probiotic showed increased fecal $\mathrm{IgG}$ and $\mathrm{IgA}$ as compared to the animals in the control group. ${ }^{22}$ In this study, Enterococcus faecium SF68 was given to group B. There was significant difference in stool frequency between control group and the group receiving Enterococcus faecium SF68 as stool frequency was reduced in a group receiving Enterococcus faecium SF68. In present study both probiotics i.e., S. boulardii and Enterococcus faecium SF68 decreased the stool output, duration of diarrhea and length of hospital stay in infants in acute severe diarrhea. There was no significant difference in stool frequency, duration of diarr-hea and length of hospital stay between group B and group C. Both probiotics also improved the stool consistency and the percentage of infants forming normally formed stool was higher in a group receiving Enterococcus faecium SF68 as compared to infants receiving S. boulardii. At day 5, $80 \%$ of patients formed normal stool in group B while $60 \%$ of patients formed normal stool in group $\mathrm{C}$. There was also significant difference in vomiting between group $\mathrm{B}$ and group $\mathrm{C}$. The episodes of vomiting at day 1 and at day 2 were less in a group receiving Enterococcus faecium SF68 as compared to group receiving S. boulardii. There are many advantages of this study like the concealment of allocation of infants into 
specific groups removed the bias. Some infants were discharged early from hospital, but the direct and continuous contact with physician maintained the quality and integrity of results. Like the advantages, there were some limiting factors of the study; the nutritional status and body weight of infants varied because the majority of patients reporting to government hospitals belong to low socioeconomic status and general health of infants is very important in terms of immunity. Moreover, the type of diarrhea (infective/ non infective) was not taken into account while selecting infants for study group.

\section{Conclusion}

This is the first study which made the comparison of the effects of S. boulardii and Enterococcus faecium SF68 in acute severe diarrhea in infants. In developing countries, the people have less exposure about the benefits of probiotics. As the children in develo-ping countries are malnourished having decreased immunity, adding specific probiotics in acute diarr-hea will help in early recovery leading to socio-economic benefits.

\section{Conflict of Interest: None}

\section{References}

1. Guandalini S. Diarrhea. [online] Available at: $<$ http:// emedicine.medscape.com/article/928598-overview \# showall $>$ [Accessed 16 October 2015].

2. Farthing M, Salam MA, Lindberg G, Dite P, Khalif I, Salazar-Lindo E, Ramakrishna BS, Goh KL, Thomson A, Khan AG, Krabshuis J, LeMair A; WGO. Acute diarrhea in adults and children: a global perspective. J Clin Gastroenterol. 2013;47(1):12-20.

3. Nahaisi MH, Ravisankar S, Noratto GD. Probiotics as a strategy to improve overall human health in developing countries. J Prob Health. 2014;2(1):1-9.

4. Phad A. Probiotics: Biotherapeutic agents in the human health. JADD. Jan 2014 3;1(1):929.

5. Feizizadeh S, Salehi-Abargouei A, Akbari V. Efficacy and safety of Saccharomyces boulardii for Acute Diarrhea. Pediatrics. 2014;134(1):176-191.

6. Applegate JA, Walker CLF, Ambikapathi R, Black RE. Systematic review of probiotics for the treatment of community-acquired acute diarrhea in children. BMC Public Health 2013;13(3): 1-8.

7. Michail S, Harb R, Botros AM. An Update on Probiotic Safety and Efficacy. Ann Pediatr Child Health. 2015;3(2):1042.

8. Hatta M, Supriatmo, Ali M, Sinuhaji AB, Hasibuan
B, Nasution FL. Comparison of zinc-probiotic combination therapy to zinc therapy alone in reducing the severity of acute diarrhea. Paediatr Indones. 2011; 51(1): 1-6.

9. Canani RB, Cirillo P, Terrin G, Cesarano L, Spagnuolo MI, De Vincenzo A, Albano F, Passariello A, De Marco G, Manquso F, Guarino A. Probiotics for treatment of acute diarrhoea in children: randomised clinical trial of five different preparations. BMJ. 2007 ;335(7615):340-342.

10. Khan A, Javed T, Chishti A L. Clinical efficacy of use of probiotic "Saccharomyces boulardii" in children with acute watery diarrhea. Pak Paed J. 2012; 36(3): 122-127.

11. Grandy G, Medina M, Soria R, Terán CG, Araya M. Probiotics in the treatment of acute rotavirus diarrhoea: A randomized, double-blind, controlled trial using two different probiotic preparations in Bolivian children. BMC Infect Dis. 2010;10(1):253-259.

12. Kosek M, Bern C, Guerrant RL. The global burden of diarrhoeal disease, as estimated from studies published between 1992 and 2000. Bull World Health Organ. $2003 ; 81(3): 197-204$.

13. lker CL, Aryee MJ, Boschi-Pinto C, Black RE. Estimating diarrhea mortality among young children in low and middle income countries. PLoS One. 2012; 7(1):1-7.

14. Burande MA, Burande AR. Efficacy of Saccharomyces boulardii strain in acute diarrhea in children : An Indian Perspective. Int.J. Recent Trends Sci. Technol. 2012; 4(1):41-44.

15. Hotiana NA, Raza MH, Ayub R. Efficacy of Saccharomyces boulardii Vs Zinc Supplementation in the Management of Acute Childhood Diarrhoea. PJMHS. 2015; 9(4):1334-1337.

16. Shaikh F, Bhand SA, Kumar P, Nizamani MA. Acute diarrhea; role of Saccharomyces boulardii in the treatment. Professional Med J. 2015;22(3):281-286.

17. Azim K. Efficacy of Probiotics ( Saccharomyces boulardii ) in Acute Watery Diarrhea in Children. JRMC. 2014;18(2):216-218

18. Erdogan O, Tanyeri B, Torun E, Gonullu E, Arslan H, Erenberk U, Oktem F. The comparition of the efficacy of two different probiotics in Rotavirus gastroentiritis in children. J Trop Med. 2012;(2012):1-5.

19. Vandenplas Y, Brunser O, Szajewska H. Saccharomyces boulardii in childhood. Eur J Pediatr. 2009; 168(3):253-265.

20. Williams NT. Probiotics. Am J Health Syst Pharm. 2010; 67(6): 449-458.

21. D’Apuzzo V, Salzberg R. 1982. [Treatment of acute diarrhoea with Streptococcus faecium in paedtiatrics: results of a double blind study]. Ther Umsch. 1982; 39(12):10331035. 
22. Benyacoub J, Czarnecki-Maulden GL, Cavadini C, Sauthier T, Anderson RE, Schiffrin EJ, von der Weid T. Supplementation of food with Enterococcus faecium (SF68) stimulates immune functions in young dogs. J Nutr. 2003;133(4):1158-62.

\section{Authors Contribution}

KAF: Concept, Design, Data Acquisition,
Interpretation, Literature search, Manuscript writing KZM: Literature search, Data Interpretation, Manuscript writing

RMA: Critical revision, Manuscript formatting

IZ: Literature search, Statistical Analysis

PF: Data Collection \& Analysis

CS: Critical revision, Proof Reading 